\title{
Women's employment, segregation and skills in the future of work ${ }^{1}$
}

\section{Abstract}

Discussion of the future of work has focused a lot on the type or number of jobs that new technology will create or destroy. Little consideration has been given to how gender fits into this. This article examines this by considering: (a) the automatability of male and female jobs; (b) employment projections for male and female jobs; (c) past and projected sex segregation of employment; and (d) past and projected skill levels of male and female jobs. Our analysis makes use of historical data and projections for the Australian and US labour markets. It appears that neither technological change nor other structural changes in labour markets are likely to especially disadvantage women. If anything, women's jobs are slightly more secure (or less insecure) than men's; there has been, and will be, an improvement in the skill levels of jobs held by women; and there has been a small reduction in average sex segregation. However, developments within specific industries are important and difficult to predict. In that respect, the information and communications technology (ICT) occupations go against the trend elsewhere, having experienced undergone a transformation in their gender composition that is reinforcing, rather than weakening, gender segmentation.

\footnotetext{
${ }^{1}$ Pre-publication version. Check against published version as some corrections and editorial changes were subsequently made before publication.
} 


\section{Women's employment, segregation and skills in the future of work}

Discussion of the future of work has focused a lot on the type of jobs that new technology will create or destroy and, to a lesser extent, the nature of employment or contracting relationships related to the growth of platform technologies. Little consideration has been given in academic literature to how gender fits into this. This article seeks to redress part of that lacuna. We focus on a particular aspect of the gendered future of work, specifically: Are women likely to lose their jobs through future changes in the labour market? In particular, will automation and artificial intelligence - that is, technological change-be costlier for women than for men? Are trends likely to reduce or increase gender segregation of employment and skills in the labour market?

The structure of this paper is to first consider key elements in the recent literature on the number of jobs available to both sexes, especially as this is relevant to our subsequent methodology. We then briefly discuss recent literature on gender in the future of work. Next we outline our methodology for the rest of the paper, and present our findings on the likely gender composition of future employment.

\section{The future of employment}

How many jobs?

There are two main estimates that have been made of the number of jobs that will be eliminated by new technologies, $\mathrm{AI}$ and automation. The first one, which 
received a considerable amount of publicity, came from two University of Oxford researchers, Frey and Osborne, and was published in 2013. It found that '47 per cent of total US employment is in the high risk category' (Frey and Osborne, 2013, 38). Their technique was largely reproduced, for an Australian audience, by Durrant-Whyte and colleagues. Their work was released in 2015 as part of a CEDA publication, and found that ' 40 per cent of current jobs have a high probability...of being computerised or automated in the next 10 to 15 years' (Durrant-Whyte, McCalman, O'Callaghan, Reid and Steinberg, 2015, 60). The method used by Frey and Osborne involved asking an expert panel to assign each of 70 occupations, into 'automatible' (their term) or 'not automatible' categories, quantifying the characteristics or tasks of those jobs and, using US data, estimating the probability of automation of the other 632 US occupations for which they could get data.

The alternative view, put by three German researchers writing a study for the OECD - Arntz, Gregory and Zierahn—and published in 2016, looked at data about individual jobs, not whole occupations, and concluded that 'on average across the 21 OECD countries, 9 per cent of jobs are automatable', and the figure was the same for the US (Arntz, Gregory and Zierahn, 2016, ). Unfortunately, Australia was not one of the 21 countries they produced estimates for. In effect, they took as their starting point Frey and Osborne's estimates for occupations but then applied those data to what individual employees said about their own work in another study (the Programme for the International Assessment of Adult Competencies that surveys task structures across OECD countries). 
Our assessment is that Frey and Osborne's large numbers do not tell us anything about how many jobs are going to be displaced, because occupation is too broad a category, and that the OECD researchers are probably closer to the mark (see also Dunlop $(2018$, , 177.) However, neither tells us about how much unemployment will be created by technological change, for two main reasons. First, these estimates take no account of the cost of new technology-many technological solutions are never applied because they are too expensive relative to the cost of continuing to use human labour. Second, they do not attempt to take account of the number and the types of jobs that will be created by the increased spending power of consumers who no longer need to use as much of their income on products whose price has fallen.

An alternative approach taken in Australia by a consultancy firm, Alphabeta (2017, ), was to take the US occupational database, $0^{*} \mathrm{NET}$, and use it to estimate the time spent on each of six types of tasks (interpersonal, creative and decision-making, information synthesis, information analysis, unpredictable physical and predictable physical) in each of 350 Australian occupations, though these appeared to be aggregated into 973 -digit occupations. It then assumed that the first three tasks were difficult to automate and the last three were automatable, and on that basis estimated the proportion of each jobs time was automatable. In inferred that, on average, 35 per cent of time presently spent at work could be automated, but observed that 'automation will change the jobs we do, but it will mostly change the way we do our jobs' and concluded (or perhaps started-it is in the title) that 
'Australia can seize a $\$ 2$ trillion opportunity from automation and create millions of safer, more meaningful and more valuable jobs' (Alphabeta, 2017, 1, 12, 1, 12). Alphabeta claim that their approach to calculating automatability has the advantage of being 'objective', though this is slightly simplistic, as it still rests on the very subjective assumption that, for each occupation, time spent doing manual and information analysis tasks is automatable whereas time spent doing other tasks is not. Frey and Osborne's approach appears initially more subjective but ultimately applies an algorithm to calculate automatability probabilities for most occupations that is based on less simplistic assumptions.

In all of this, there is an important gender dimension, but it has been ignored in much of the writing. We wish to remedy that here.

\section{Writings on gender in the future of work}

One of the enduring characteristics of western labour markets, including those in Australia and the US, is sex segregation of employment. In most western societies, the interface between the domestic and market spheres, and related ideologies about what is suitable work for women and suitable work for men, have meant that certain jobs have been socially defined as 'men's work' and others socially defined as ‘women's work' (Duncan and Duncan, 1955; Karmel and MacLachlan, 1986; Watts and Rich, 1992; Chang, 2000; Barón and Cobb-Clarke, 2008; Blau, Brummund and Liu, 2012; Workplace Gender Equality Agency, 2016, ). Those defined as 'women's work' have most commonly been associated with household tasks performed within the household by women, according to gendered divisions 
of household labour, particularly in earlier stages of capitalism. These jobs also tended to have low status and be undervalued and underpaid (Peetz and Murray, 2017, ). The division of labour reinforced male power both in domestic and market spheres, so 'male' jobs included those involving physical labour not associated with former household activities (such as laundry work which was traditional female work, even though it was physically exhausting), as well as jobs involving positions of power (such as senior managers), authority (lawyers) or perceived technical expertise (engineers, architects, university professors, and information technology specialists). Even clothing associated with particular jobs signified superior (male) or inferior (female) roles (Cremin, 2018, )

Since the 1960s, women have entered the labour market in increasing numbers, and female participation has grown relative to men's (International Labour Office, 2016, ). Women have challenged male dominance in a number of fields. Yet it is not so clear whether sex segregation within the labour force has substantially improved in recent years. In the US, it appears that early, quite rapid reductions in sex segregation in the 1970 s and, to a lesser extent, the 1980s, subsequently slowed, with little decline over the 2000s (Blau, Brummund and Liu, 2012, ). Indeed, the female employment share in male-dominated industries appeared to fall between 1995 and 2010 (Soltas, 2012, ). Looking at Europe after the financial crisis, Piasna and Drahokoupil (2017) found signs of upgrading in the female occupational structure, but female-dominated segments still constituted the main drivers of female job growth and overall there was nothing to signal a major break with the gendered division of jobs. 
For some researchers, looking at the future of women and work has involved asking them about how positive or negative they felt about various matters that were relevant to their future prospects. Hence Baird, Cooper, Hill, Probyn and Vromen (2018) surveyed 2000 Australians and found that only two in five women currently working felt they could access free or affordable training, equipping them for better jobs. Those most likely to agree were more commonly tertiary educated, in the public sector, working from home or not casuals or 'freelancers'. Only one in five-similar for men and women—believed their job would not exist in its current form in 20 years time. Yet overall, women were more optimistic than men about automation and their jobs. Men were considerably more likely than women (by 39 to 28 per cent) to be somewhat or very concerned about potentially losing their job because machines or computer programs will be used to replace human workers. By a similar margin, men were more likely than women to be concerned about losing their job due to their industry shrinking, and by a margin of 32 to 19 per cent to be concerned about losing it because they are not able to keep up with the technical skills required.

For the authors, though, addressing existing gendered inequities in employment are important issues for the future. A related view is expressed by politician McAllister (2016), who argues that automation will entrench gender work inequalities unless gender issues are directly addressed. By contrast with the relatively positive view of automation held by respondents to Baird et al., 's survey, Piasna and Drahokoupil (2017), who examined patterns in employment growth in 
Europe, considered that the current division of tasks rendered women 'more vulnerable to automation'. They observed, though, trends from recent years 'point to a narrowing of the gender gap through upgrading' of skills in the near future.

Finally, although the Alphabeta (2017) analysis of jobs contained no gender analysis, two Australian Broadcasting Corporation journalists obtained its data for 97 occupations (disaggregated at a detailed, 3-digit level) and linked to data from the Australian Bureau of Statistics (ABS) on gender (Hanrahan and Evlin, 2017, ). They concluded that 'men's jobs are easier to automate than women's jobs' on the basis of a strong correlation ( $\mathrm{r}=0.40)$ across occupations between female employment share and Alphabeta's estimate of the proportion, and that 'there are about 2 million Australian men working in jobs where more than half of the job is at risk of automation. That compares with about 750,000 women in such roles' with similar risk (Hanrahan and Evlin, 2017, ).

\section{Methodology}

Because of the high and mostly persistent level of gender segregation of jobs, it is useful to refer to and analyse 'male' and 'female jobs', even though these concepts are socially constructed. Our starting point was to estimate the risk of automation in male and female jobs at the occupation level, using Frey and Osborne's estimates of 'automatability' (their neologism) for individual US occupations. We used their estimates because they are publicly available, and their approach of using an expert panel and then applying the findings more broadly through regression 
analysis was as good as any we can find, and quite suitable for our purposes, as we are interested in the susceptibility of work to automation. We are not unique here: even Arntz et al (2016) used Frey and Osborne's estimates as a starting point (as mentioned, their disagreement with Frey and Osborne was essentially about the unit of analysis - whether it should be the occupation as a whole or the individual employee's job).

We then linked Frey and Osborne's data on 'automatability'.to estimates on the gender composition of occupational employment from the US Current Population Survey (CPS). The latter is a monthly labour force survey administered by the US Bureau of Labor Statistics. We found matches for 300 occupations. This number represents less than half the number of occupations with automatability as estimates made by Frey and Osborne, due to different levels of disaggregation and differences in occupational descriptors. However, these matches covered 93 per cent of the CPS sample. This high ratio was because most occupations that lacked a gender estimate in the CPS were small occupations with two few observations for reliable estimates. This method, therefore, had very high coverage across the US labour force. The important thing here was not the absolute value of the 'risk of automatability', it was the relative value of this between males and females. Even if Frey and Osborne's method of generalising to the population led, in our view, to an overestimate of the total number of jobs lost, we have no reason to believe that it contained systematic bias with respect to gender. We therefore have no reason to think that it would lead to an overstating or understating of the relative automatability of male and female occupations. 
We presented our results from that analysis in two ways. First, we show the average rate of automatability in each of three categories: male-dominated occupations ( $>60$ per cent male employment), female-dominated occupations $(>60$ per cent female employment) and mixed occupations (40-60 per cent of each sex). These averages are, in turn, expressed in two different ways: an unweighted average that treats all occupations as equal in size; and a weighted average that (more realistically) accounts for the different sizes of different occupations. To provide some context, we also show the gender composition of employment in each of the groups of male-dominated, female-dominated and mixed occupations.

Second, we calculated the average probability of automation of a 'male' and 'female' job. This in effect adds up the probability of employability of each job occupied by a male, and each job occupied by a female, in the US labour market. One reason for doing this is that, despite what we know about gender segmentation on the labour market, there is still an element of arbitrariness in drawing the line that determines male- or female-'dominated' fields—should it be 80,60 or 51 per cent? In practice, when we rank occupations or industries by their gender composition, there is no obvious break defining where to the line should be drawn. Calculating the average probability of automation of 'male' and 'female' jobs removes the relevance of such arbitrary definitions. This approach fundamentally assumes that the relative gender character of jobs will not change in the short term and, while the shares of men and women in a particular occupation may vary over time, instances of gender 'flipping' — of an occupation 
shifting from male- to female-dominated or vice versa, are relatively rare, though notable when documented (Kelly and Forbath, 1992; Brosnan, 1996, ).

Second, as a reality check on the first, we looked at the employment projections of the US Bureau of Labor Studies (BLS) and broke them down by gender. That is, we took at face value the ten-year (2026) BLS employment projections by occupation, which are not disaggregated by gender, and applied gender weights to the forecast employment in each occupation based on the share of men and women in employment in each occupation in 2016. This gave us data for a total of 837 occupations (higher than the previous $\mathrm{N}$ because no matching was required). Again, we report our results in two ways: first, showing average projected employment growth in each of the male-dominated, female-dominated and mixed occupations; and second showing average projected employment growth for male and female jobs. The latter estimate treats all jobs occupied by men, and by women, within a particular occupation as having equal growth prospects.

We then move to an analysis of the Australian labour market, where we have consistent data available at the 4-digit occupational level covering the period from late 1986 to early 2018 and occupational projections for the period 2017-2022. We do not seek to replicate the first part of the above methodology in the Australian context, as the occupational definitions differ between the USA, used by Frey and Osborne, and Australia; but we do apply the second approach (looking at the gender composition of employment projections). We also compare those projections with longer term historical trends. The historical data come from the 
ABS and the projections came from the Australian Department of Jobs and Small Business (until recently, the Department of Employment or DE). In the historical data, we consider developments over a period of nearly three decades, from the triennium 1986-87 to $1988-89$, to the triennium $2015-16$ to $2017-18$. We have used trienniums to minimise the effects of sampling error in assessing these long term trends. For convenience we sometimes refer to these periods as T1 and T2 respectively.

The Department's estimates for the starting point in time (in this case, May 2017) comprise a seasonally adjusted and trended estimate of employment in each industry down to the 3-digit level; and a seasonally adjusted and trended estimate of employment in each industry and state at the 1-digit level. The projections cover the period to May 2022 (we call this T3). The Department's projections are a combination of models that use autoregressive integrated moving and exponential smoothing with damped trend approaches, but they are adjusted by research and information obtained by the Department on likely future industry, occupational and regional developments. We do not accept these predictions without reservation; they are just the best that are available. The difficulty of making them is illustrated by earlier, simultaneous predictions on coal industry employment: in 2015 private firm Ibis World forecast 9 per cent growth in employment in black coal over the period from 2015-16 to 2020-21, revising this by April 2016 to of just 2.8 per cent, while the Department of Employment was forecasting 20 per cent decline by 2020 (Department of Employment, 2016; Ibis World, 2016, ). Nonetheless, an earlier version of these Departmental projections was used by the 
CSIRO in its widely discussed 'Data 61' report on 'Tomorrow's Digitally Enabled Workforce' (Hajkowicz et al., 2016, ). As the projections are from a single point in time (May 2017), whereas the historical analysis goes to a triennium averaged (2015-16 to 2017-18) there are slight differences, of no consequence, between the 'current' estimates for the T2 historical data and projections shown in Table 3.

Again, for reality check purposes, we also undertook further analysis of the Alphabeta data used by Hanrahan and Elvin (2017, ) on Australian automatability by gender, along similar lines to that described above.

Aside from the gender composition of future employment, two other matters are of particular interest: gender segregation and skills. The first we examine by use of a well-used index of dissimilarity, the Duncan segregation index (Duncan and Duncan, 1955, ). It essentially depicts the proportion of people who would have to change occupations in order to achieve parity of (gender) representation in each occupation (ie in proportion to that gender's share of the employed labour force), and ranges in value from 0 (no segregation) to 1 (total segregation). We calculated it by the formula:

N

$1 / 2 \sum\left|m_{i} / M-f_{i / F}\right|$

$i=1$

where

$\mathrm{m}_{i}=$ the male population of the $i^{\text {th }}$ occupation; 
$\mathrm{M}=$ the total male population of the national labour force;

$\mathrm{f}_{i}=$ the female population of the $i^{\text {th }}$ occupation; and

$\mathrm{F}=$ the total female population of the national labour force.

To assess skill, we use the skill level that the Department associates with each 4digit occupation. There are five skill levels and they range from 1 (highest) to 5 (lowest) with skill level 1 being commensurate with a Bachelor degree or higher qualification, skill level 2 with an Advanced Diploma or Diploma, skill level 3 with a Certificate IV or III (including at least 2 years on-the-job training), skill level 4 with a Certificate II or III, and skill level 5 with a Certificate I or secondary education. We thus allocate each occupation to one of the five skill levels, and estimate its growth and share of total employment by gender.

\section{Findings}

\section{Automatibility}

We analysed the potential 'automatability' of US jobs as described above. The findings are in Table 1.

The first panel of Table 1 provides context, showing that slightly under half of US occupations for which there are matched data are male dominated, and these account for around 44 per cent of employment in the dataset; while slightly under a third of occupations are female dominated; and these account for 36 per cent of employment. The second panel, providing results, shows that the weighted average automatability risk is 50 per cent for workers in male-dominated 
occupations, whereas it is only 44 per cent for workers in female-dominated occupations (and also for those in mixed occupations). While these numbers may all seem to imply a high risk of automation, remember that our interest is in their relative value, not the absolute value. So the point of note is that male-dominated occupations have a weighted automatability risk about 6 percentage points (or roughly 13 per cent) higher than do female-dominated occupations.

Overall, the average automatability risk of male jobs as calculated through this method is 48.8 per cent, compared to the average risk for female jobs of 44.1 per cent (Panel 3). That is, male jobs, on average, have an automatability risk that is nearly 5 percentage points (or about 11 per cent) higher than do female jobs.

The above analysis of the jobs that are likely to be automated, at least according to Frey and Osborne, suggests that the gender differences in effects are not big, and if anything men's jobs are slightly more likely to be automated than women's jobs. It looks like, to put it simply, Piasna and Drahokoupil (2017) were wrong on the gender effects of automation and the participants in Baird et al., 's (2018) survey were right.

\section{Employment growth in the US labour market}

The results of our analysis of employment growth projections by the BLS are in Table 2. They show that, consistent with the analysis of automatability in Table 1, female-dominated occupations are projected to (slightly) increase their total share of US employment to 2026, and male-dominated occupations to (slightly) reduce 
their share. The four occupations with the largest projected contributions to employment growth (in absolute numbers, not percentages) have female majorities in 2016: personal care aides; nursing, psychiatric, and home health aides; registered nurses; and combined food preparation and serving workers, including fast food. The first two of those are also amongst the ten fastest-growing (in percentage terms) occupations of any size, and are part of the six femalemajority occupations in that list of the fastest ten. Most of the male-dominated occupations in that fastest ten list are small, with one notable exception: software developers, applications and systems software, which account for one fifth of jobs in that list of the fastest ten (personal aides alone account for nearly half, and nursing, psychiatric, and home health aides over another fifth). If we assume that the gender composition of employment of each occupation is constant over the period, then overall female employment is projected to grow by 8.0 per cent over the decade, and male employment by 6.8 per cent.

As we have discussed, some of the largest employment growth is likely to be in care-related jobs, like aides and carers and health professionals, which have higher rates of female employment than many manual jobs. This is a factor in the lower rate of automatability amongst female jobs. 
The results of our analysis of employment data from the ABS over the period from 1986, and employment growth projections by the Department of Jobs and Small Business are in Table 3. Panel 1 of the table is historical, and panel 2 prospective. In both panels, whether an occupation was male or female dominated was determined by its 'current' female employment share (that is, its female employment share in the triennium 2015-16 to 2017-18).

\section{TABLE 3 APPROXIMATELY HERE-}

As shown in panel 1 of the table, occupations that are now female-dominated occupations grew from 34.4 per cent of total employment in the early period, 1986-87 to $1988-89$, to 37.2 per cent of total employment in the current triennium, 2015-16 to 2017-18. Occupations that are now male-dominated occupations fell from 47.1 to 41.4 per cent of total employment. Thus there has been a growth in female-dominated occupations that is quite distinct from the overall growth in female employment and labour force participation over the past three decades.

Panel 2 of Table 3 shows that, consistent with the analysis of the US labour market in Table 2, female-dominated occupations are projected to (slightly) increase their total share of total Australian employment to 2022, and male-dominated occupations to (slightly) reduce their share. The biggest contributions to future employment growth is projected come from aged and disabled carers, registered nurses, child carers, followed by general sales assistants (though they have only a 4.7 per cent growth rate projected-it is their large numbers to begin with that see 
them on this list), general clerks (a similar comment applies), and education aides. If we assume that the gender composition of employment of each occupation is constant over the five-year period, then overall female employment is projected to grow by 9.1 per cent over the period, and male employment by 6.5 per cent. These relativities between projected male and female employment growth are remarkably similar in the two labour markets.

Our reality check, using the Alphabeta data analysed by Hanrahan amd Evlin (2017, ), found results consistent with this broad pattern. On average, some 39.2 per cent of the time spent on men's jobs, but only 30.9 per cent of the time spent on women's jobs, lent itself to automation. This differential is in the same direction as, but larger than, that arising from our analysis of US jobs, but that difference in size probably reflects methodological differences and the higher level of aggregation used (only 97 occupations rather than 300). Still, the gap may seem smaller than implied by the writings of Hanrahan amd Evlin $(2017$, ), but that reflects the detailed distribution of automatability: for example, by Alphabeta's measure, of the five most automatable jobs, the two largest (Food Preparation Assistants and Cleaners and Laundry Workers) are both female-dominated. The direction of results is consistent with that in the other analyses, but their finergrained approach (that is, using more detailed occupational categories) probably enable more accurate estimates to be made.

\section{Segregation}


Estimates of gender segregation in the labour market are shown in Table 4. The main results, relevant to the labour force as a whole, are shown in the left hand data column. They suggest a small reduction in gender segregation in the labour market over the almost three decades covered by the data to the current time (that is, to the triennium 2015-16 to 2017-18, in Panel 1). While this may intuitively seem surprising to some, it happened because there were, on average, declines in the female share of employment in the most heavily female-dominated occupations (those with an over 80 per cent female composition in T1) and increases in the female share of employment in male dominated occupations (those with an over 60 per cent male composition in T1).

\section{TABLE 4 APPROXIMATELY HERE}

The effect on gender segregation of projected occupational growth patterns is shown in Panel 2 of Table 4. A small further reduction in gender segregation is forecast for the five years to 2022 . While this seems especially small compared to the movements to date, it should be remembered that those occupational projections can only account for between-occupation variations in growth rates. Comparing like with like, the projected effects of between-occupation employment growth on gender segregation over the coming five-year period aligned almost directly with the past experience of between-occupation employment growth over a three-decade period, almost six times longer. 
Indeed, when we consider the historical data we see that, while the differential pattern of growth by industry helped reduce gender segregation (that which is referred to as 'between-industry employment growth' in Table 4), the bigger factor was 'within-industry employment patterns'. Women appeared, in a disproportionate amount, to newly move into those occupations that were experiencing employment growth, presumably because strong employment growth would minimise resistance to what might otherwise be seen as interlopers. This is important for interpreting projections of employment growth discussed earlier. All projections by gender assume (as they must) that the gender composition of an occupation will remain constant, but experience tells us that this assumption has its limitations, as women entering the labour force exercise agency in choosing occupations (and industries) that are likely to grow. If anything, the projections of female employment growth in the US and Australian labour markets made earlier will likely understate the differential between future male and female employment outcomes.

While some occupations varied from the historical pattern described above, there was an exception so noteworthy that we separately discuss it here. That is the information and communication technology (ICT) occupations, whose effect is so significant we make allowance for it in the last two columns of Table 4 . In the late 1980s, in T1, females accounted for 33.6 per cent of employment in ICT occupations. By the current period, T2, females accounted for just 20.2 per cent of employment. That is, the female share of employment in ICT occupations fell by 13.4 percentage points (about two fifths). This occurred over a period when, 
amongst the rest of occupations that had an initial female employment share of 20 to 40 per cent, the female employment share grew by an average of 12.5 percentage points. While women were entering many other male-dominated occupations in growing numbers, they were, in relative terms, being pushed out of the ICT workforce.

The impact of this can be seen by comparing what segregation would be with, and without, the inclusion of the ICT occupations, as depicted in the last two columns of Table 4. In T1, the ICT occupations actually slightly dragged down the Duncan segregation index. This may seem counter-intuitive, as ICT was male-dominated even then, but it was because in $\mathrm{T} 1$ the level of male-domination was not all that far from the average level of male domination in the workforce as a whole $(40.1$ per cent), and well under a standard error from it. But while gender segregation in other occupations, on average, improved, in the ICT occupations it worsened. So by $\mathrm{T} 2$, the inclusion of the ICT occupations worsened the Duncan segregation index. In T1, some 14.7 per cent of women worked in occupations that had a lower share of female employment than ICT; but by T2, only 3.8 per cent of women worked in occupations that had a lower share of female employment than ICT. The ICT sector has developed into a major source of problems for female workers, with issues ranging from career impediments to harassment (Ensmenger, 2010; Dockterman, 2014; Kessler, 2015; Keane, 2016; Zarya, 2016; Hicks, 2017; Levin, 2017; Naughton, 2017; Piasna and Drahokoupil, 2017, , and the problems there are possibly more substantial than has previously been recognised. It is not just a male-dominated occupation, it is one that is moving in the opposite direction to 
most other male-dominated occupations in that its inclusion of women is substantially worsening, and it is one that is itself critical in shaping the future of work.

There is one other remark to make about segregation. While in most maledominated occupations advances in female representation had been made, in the most heavily male-dominated occupations (those with over 90 per cent male employment in T1) progress was slow. In those, the average employment shares of women rose by only 2.9 percentage points (compared to 12.5 percentage points across other male-dominated occupations). While there were some exceptions where major inroads by women were made into previous male bastions (such as ambulance officers and paramedics, chemical and materials engineers, architects, insurance investigators and legislators), many trades areas in particular appeared resistant to change.

\section{Skill}

Table 5 shows the effects of changes in the occupational mix on skill levels of jobs over the previous three decades (in Panel 1), and the projected effects over a coming five-year period (in Panel 2). The historical data in Panel 1 reveal the 'upskilling' of both male and female jobs, that is a higher proportion of jobs in skill level 1 , which require a university degree, and a lower proportion in skill level 5, in T2 compared to T1. This upskilling was much greater for women (amongst whom there was an 11.9 percentage point increase in level 1 jobs) than for men (amongst whom the increase was just 5.5 percentage points. This is closely related to the 
changes in education patterns: the majority of university students are now women, whereas this was not the case in the 1980s. Hence there are now slightly more women in level 1 jobs than men, the reverse of three decades ago. Indeed, the gender differences here are partly obscured by the role of the ICT occupations, many of which are level 1. ICT occupations account for a third of the growth in level 1 jobs for men, compared to little more than one fortieth of the growth in level 1 jobs for women.

The projections are for this broad pattern to continue. The growth of the share of women in level 1 jobs would again be about double the growth of the share of men in level 1 jobs if current occupational predictions are correct and the relative gender composition of occupations remains stable. Whether this in turn helps reduce the gender pay gap is another matter altogether, as there are many other factors than just the pattern of employment that shape the gender pay gap, including the extent of undervaluation of female-dominated jobs, the extent to which norms and regulation allow the underpayment of women in maledominated jobs, and the extent to which 'gender flipping' might influence the characteristics of some particular high-paid or low-paid jobs (Peetz and Murray, 2017, ).

Across both sexes, over the next five years, the fastest employment growth rate, and the greatest contribution to employment, are still expected to be made by the 
highest skill level group (skill level 1). Yet, the annual rates of growth in the shares of level 1 skilled occupations would seem to be somewhat slower in the future than in the past for both sexes. The next highest projected growth rate, on average, would be amongst skill level 2. But interestingly, skill level 4 is projected to have considerably faster growth than skill level 3 (which is expected to be the worst of all five groups). The biggest factor in the expected growth of skill level 4 is the growth in aged and disabled carers—that occupation alone accounts for over a quarter of total employment growth in skill level 4, so amongst women skill level 4 will be that with the second fastest growth, but amongst men it will be ranked just third. By contrast, over the previous three decades, the contribution of skill level 4 to women's employment had declined. In short, it looks like the trend towards upskilling of women's work will be slowed, but not halted, as the growth of aged care work provides an opportunity for some job growth at relatively low skill levels.

\section{What the data do not show}

Having made these estimates, we wish to emphasise their significance should not be overstated. They do not demonstrate that men, rather than women, will be the victims of technological change over coming years. For one thing, these numbers are averages, and they disguise a huge amount of variation between particular occupation. Some of the occupations with the highest risks of automatability (e.g. data entry keyers; paralegals and legal assistants; bookkeeping, accounting, and auditing clerks; models, demonstrators, and product promoters; tellers; receptionists, secretaries and administrative assistants; hosts and hostesses in 
restaurants, lounges, and coffee shops) have very high female employment—while some others amongst the lowest automatability scores also have high female employment (registered nurses; preschool and kindergarten teachers; meeting, convention, and event planners; maids and housekeeping cleaners; hairdressers, hairstylists, and cosmetologists; occupational therapists; dietitians and nutritionists). Specific occupations will be the sites of contestation over the introduction of new technology, but gender will not be the factor that determines whether those jobs are automated. It might, however, have an influence on the outcome. This is not because women are less activist or less well organised as workers than men-evidence suggests this is not the case (e.g. Grimes, 1994, ). Rather, it is because some occupations or industries may be the sites of gender contestation. This might occur if males become displaced from related occupations and then behave consistent with seeking to (re)colonise another occupation. Alternatively contestation may occur if technological change leads to potential changes in the status of an occupation: status changes have been held responsible by Kelly and Forbath (1992) and Brosnan (1996) for instances of occupations shifting from male- to female-dominated or vice versa. The change in the gender composition of ICT industries can also be seen in light of changing occupational status (Hicks, 2017, ).

In short, the significance of the above numbers is in what they do not show. They do not show that women are about to be disproportionately replaced by robots. They do not show that technological change represents a special threat to female employment. From the above analysis, however, we can infer that the impact of 
new technology on women's employment will be specific to particular occupations or industries, not generalised, and needs to be considered at this level.

\section{Conclusion}

Overall, the data here suggest that neither technological change nor other structural changes in labour markets are likely to especially disadvantage women. If anything, women's jobs are slightly more secure (or less insecure) than men's. This is consistent with survey data looking at the perceptions of men and women as to their employment futures (Baird et al., 2018, ).

It also appears that there has been, and will be, an improvement in the skill levels of jobs held by women, though at a slower rate in the near future than in the recent past and with more unevenness due to the expected growth in aged and disability care. We also conclude that there has been a small reduction in average sex segregation, in the Australian labour market at least, and the structural forces affecting this are likely to continue into the near future-though these structural forces affecting differences in the growth of employment between occupations do not appear to be as strong as developments within specific industries, and these are much more difficult to predict.

In that respect, the ICT occupations stand out as running against the trend experienced by most male-dominated occupations. In most, to varying degrees, the trend was for reductions in barriers to women's employment and greater female participation in those industries. The reverse has been the case in ICT 
occupations. This is not just a case of saying that, as there is much in the media about how few females work in ICT occupations already, finding that few women are expected to benefit from any growth in ICT jobs is neither surprising nor unexpected. ICT occupations have undergone a transformation in their gender composition which is now undermining the trend towards reduced gender segmentation. We wonder whether sanguine expectations about the direction of gender segregation could be reversed if that pattern in ICT were to continue or that experience were to be replicated in other well paid, rapidly growing occupations. While the future of work might slightly favour women, it might still be men making the key decisions that shape what work looks like. So the key challenges for women are not about 'who gets replaced by machines?' but the universal one of 'who has power to control the machines that increase the scope for capital accumulation?'

\section{References}

Alphabeta (2017) The Automation Advantage: How Australia can seize a $\$ 2$ trillion opportunity from automation and create millions of safer, more meaningful and more valuable jobs., Sydney.

Arntz, M, Gregory, T \& Zierahn, U (2016) The Risk of Automation for Jobs in OECD Countries: A Comparative Analysis. OECD Social, Employment and Migration Working Papers No 189, Organisation for Economic Cooperation and Development, Paris. 
Baird, M, Cooper, R, Hill, E, Probyn, E \& Vromen, A (2018) Women and the Future of Work, Australian Women's Working Futures project, University of Sydney Business School, Sydney.

Barón, J D \& Cobb-Clarke, D A (2008) Occupational Segregation and the gender wage gap in private- and public-sector employment: a distributional analysis. Discussion Paper No. 3562 Institute for the Study of Labor (IZA) Bonn.

Blau, F D, Brummund, P \& Liu, A Y-H (2012) Trends in Occupational Segregation by Gender 1970-2009: Adjusting for the Impact of Changes in the Occupational Coding System. IZA Discussion Paper No. 6490 Forschungsinstitut zur Zukunft der Arbeit, Bonn.

Brosnan, P (1996) 'Labour Markets and Social Deprivation' Labour and Industry, 7 (2) pp. 3-34.

Chang, M (2000) 'The evolution of sex segregation regimes. ' The American Journal of Sociology, 105 (6) pp. 1658-701.

Cremin, C (2018) Man made Woman, Pluto, London.

Department of Employment. (2016) "Employment projections for the five years to November 2020: Regional employment by ANZSIC Industry." Employment Projections Retrieved 18/2/18, from http://lmip.gov.au/default.aspx?LMIP/EmploymentProjections.

Dockterman, E (2014) 'What Is \#GamerGate and Why Are Women Being Threatened About Video Games?' Time. 16 October.

http://time.com/3510381/gamergate-faq/ 
Duncan, O D \& Duncan, B (1955) 'A Methodological Analysis of Segregation Indexes' American Sociological Review, 20 (2) pp. 210-17.

Dunlop, T (2018) The Future of everything: Big Audacious Ideas for a better world, New South Books, Sydney.

Durrant-Whyte, H, McCalman, L, O’Callaghan, S, Reid, A \& Steinberg, D (2015) 'The impact of computerisation and automation on future employment '. in $\mathrm{C} \mathrm{E}$ D o Australia. Australia's future workforce? CEDA, Melbourne, pp. 56-64.

Ensmenger, N (2010) The Computer Boys Take Over: Computers, Programmers, and the Politics of Technical Expertise, MIT Press, Cambridge, MA.

Frey, C B \& Osborne, M A (2013) The future of employment: How susceptible are jobs to computerisation?, Department of Engineering Science, University of Oxford, Oxford.

Grimes, P F M (1994) The Determinants of Trade Union Membership: Evidence from Two Australian Surveys. PhD thesis. Research School of Social Sciences, Australian National University. Canberra.

Hajkowicz, S, Reeson, A, Rudd, L, Bratanova, A, Hodgers, L, Mason, C \& Boughen, N (2016) Tomorrow's Digitally Enabled Workforce: Megatrends and scenarios for jobs and employment in Australia over the coming twenty years, CSIRO, Brisbane.

Hanrahan, C \& Evlin, L. (2017, 4 September) "Artificial intelligence: Men's jobs face higher risk of automation than women, low-paid workers also at risk." $A B C$ News Online Retrieved 17/10/18.

Hicks, M (2017) Programmed Inequality: How Britain Discarded Women Technologists and Lost its Edge in Computing' MIT Press, Cambridge, MA. 
Ibis World (2016) Black Coal Mining in Australia. IBISWorld Industry Report B0601, IBISWorld, Melbourne.

International Labour Office (2016) Women at Work: Trends 2016, International Labour Organisation, Geneva.

Karmel, T \& MacLachlan, M (1986) Sex Segregation: Increasing or Decreasing. Technical Paper No 40, Bureau of Labour Market Research, Canberra.

Keane, B (2016) 'Rape fears and harassment, but bright spots for women in tech, too.' Crikey! 18 March.

Kelly, R \& Forbath, B (1992) Pay equity for women in the Confectionery industry: an analysis of issues and options for change: a report. Equal Pay Series, Department of Industrial Relations, Canberra.

Kessler, S. (2015) "Tech's Big Gender Diversity Push, One Year In." Fast Company, from http://www.fastcompany.com/3052877/techs-big-gender-diversitypush-one-year-in.

Levin, S (2017) 'Accused of underpaying women, Google says it's too expensive to get wage data.' Guardian. 27 May.

McAllister, J (2016) 'Automation will embed gender inequality at work - unless we fix it now.' Guardian. 9 November.

Naughton, J (2017) 'Want to succeed in tech? Try not to be a woman....' Guardian. 11 June.

Peetz, D \& Murray, G (2017) Women, Labor Segmentation and Regulation: Varieties of Gender Gaps, Palgrave Macmillan, New York.

Piasna, A \& Drahokoupil, J (2017) 'Gender inequalities in the new world of work' Transfer - European Review of Labour and Research, 23 (3) pp. 313-32. 
Soltas, E. (2012) "Gender Inequality's New Face." Economics \& Thought, from http://evansoltas.com/2012/04/04/gender/.

Watts, M J \& Rich, J (1992) 'Labour Market Segmentation and the Persistence of Occupational Sex Segregation in Australia' Australian Economic Papers, 31 (58) pp. 58-76.

Workplace Gender Equality Agency (2016) Gender segregation in Australia's workforce, WGEA, Sydney.

Zarya, V (2016) 'Female Programmers Make Nearly 30\% Less Than Their Male Counterparts.' Fortune.com. 16 November. 
Table 1: Risk of Automatability by Occupational type

\begin{tabular}{|c|c|c|}
\hline \multirow{5}{*}{$\begin{array}{l}\text { Panel } 1 \\
\text { Male- } \\
\text { dominated } \\
\text { Mixed } \\
\text { Female- } \\
\text { dominated }\end{array}$} & \multicolumn{2}{|c|}{ Gender composition of employment } \\
\hline & $\begin{array}{c}\% \text { of } \\
\text { occupations }\end{array}$ & $\begin{array}{c}\% \text { of } \\
\text { employment }\end{array}$ \\
\hline & $46.7 \%$ & $43.7 \%$ \\
\hline & $22.0 \%$ & $20.3 \%$ \\
\hline & $31.3 \%$ & $36.0 \%$ \\
\hline & \multicolumn{2}{|c|}{ Automatability risk } \\
\hline Panel 2 & $\begin{array}{c}\text { By } \\
\text { occupation }\end{array}$ & $\begin{array}{c}\text { By } \\
\text { employment }\end{array}$ \\
\hline $\begin{array}{l}\text { Male- } \\
\text { dominated }\end{array}$ & $50.7 \%$ & $49.8 \%$ \\
\hline Mixed & $45.9 \%$ & $43.9 \%$ \\
\hline $\begin{array}{l}\text { Female- } \\
\text { dominated }\end{array}$ & $51.2 \%$ & $44.1 \%$ \\
\hline \multirow[t]{2}{*}{ Total } & $49.8 \%$ & $46.5 \%$ \\
\hline & \multicolumn{2}{|c|}{ Automatability risk } \\
\hline Panel 3 & & $\begin{array}{r}\text { Amongst } \\
\text { individuals }\end{array}$ \\
\hline Males & & $48.8 \%$ \\
\hline Females & & $44.1 \%$ \\
\hline
\end{tabular}

Source: Calculated from Frey and Osborne (2013) and Bureau of Labor Statistics Tables, Table 11: Employed persons by detailed occupation, sex, race, and Hispanic or Latino ethnicity 
Table 2: US employment projections by occupation by gender

$\begin{array}{lllll} & \begin{array}{l}\text { male- } \\ \text { dominated } \\ \text { occupations }\end{array} & \begin{array}{l}\text { mixed } \\ \text { occupations }\end{array} & \begin{array}{l}\text { female- } \\ \text { dominated } \\ \text { occupations }\end{array} & \text { total } \\ \begin{array}{l}\text { number ('000) } \\ 2016\end{array} & 63,859.8 & 32,112.8 & 60,090.6 & 156,063.2 \\ 2026 & 67,792.2 & 34,426.0 & 65,362.7 & 167,580.9 \\ \text { distribution (\%) } & & & & 100.00 \% \\ 2016 & 40.92 \% & 20.58 \% & 38.50 \% & 100.00 \% \\ 2026 & 40.45 \% & 20.54 \% & 39.00 \% & \end{array}$

Source: Calculated from Bureau of Labor Statistics Tables, Table 11: Employed persons by detailed occupation, sex, race, and Hispanic or Latino ethnicity; and Employment projections by occupation tables, Table 1.7: Occupational projections, 2016-26, and worker characteristics, 2016 (Numbers in thousands). 
Table 3: Australian employment growth and projections by occupation by gender

\begin{tabular}{|c|c|c|c|c|}
\hline & $\begin{array}{l}\text { male- } \\
\text { dominated } \\
\text { occupations }\end{array}$ & $\begin{array}{l}\text { mixed } \\
\text { occupations }\end{array}$ & $\begin{array}{l}\text { female- } \\
\text { dominated } \\
\text { occupations }\end{array}$ & total \\
\hline \multicolumn{5}{|c|}{ Panel 1 (historical data) } \\
\hline \multicolumn{5}{|l|}{ number ('000) } \\
\hline $1986-87$ to $88-89$ & $3,395.42$ & $1,327.61$ & $2,480.70$ & $7,203.73$ \\
\hline $\begin{array}{l}2015-16 \text { to } 17-18 \\
\text { distribution (\%) }\end{array}$ & $4,985.41$ & $2,588.46$ & $4,479.05$ & $12,052.91$ \\
\hline $1986-87$ to $88-89$ & $47.13 \%$ & $18.43 \%$ & $34.44 \%$ & $100.00 \%$ \\
\hline $2015-16$ to $17-18$ & $41.36 \%$ & $21.48 \%$ & $37.16 \%$ & $100.00 \%$ \\
\hline \multicolumn{5}{|c|}{ Panel 2 (projections) } \\
\hline \multicolumn{5}{|c|}{ number ('000) } \\
\hline 2017 & $5,003.22$ & $2,472.81$ & $4,465.87$ & $11,941.91$ \\
\hline $\begin{array}{l}2022 \\
\text { distribution } \\
(\%)\end{array}$ & $5,273.04$ & $2,679.89$ & $4,914.25$ & $12,867.18$ \\
\hline 2017 & $41.90 \%$ & $20.71 \%$ & $37.40 \%$ & $100.00 \%$ \\
\hline 2022 & $40.98 \%$ & $20.83 \%$ & $38.19 \%$ & $100.00 \%$ \\
\hline
\end{tabular}

Source: Calculated from ABS Cat No 6291.0.55.003 - EQ08 - Employed persons by Occupation unit group of main job (ANZSCO), Sex, State and Territory, August 1986 onwards and Department of Jobs and Small Business. "2018 Employment Projections." Employment Projections, http://lmip.gov.au/default.aspx?LMIP/EmploymentProjections. 
Table 4: Duncan Segregation Indexes, 1986-87 to 1988-89 and 2015-16 to 2017-18

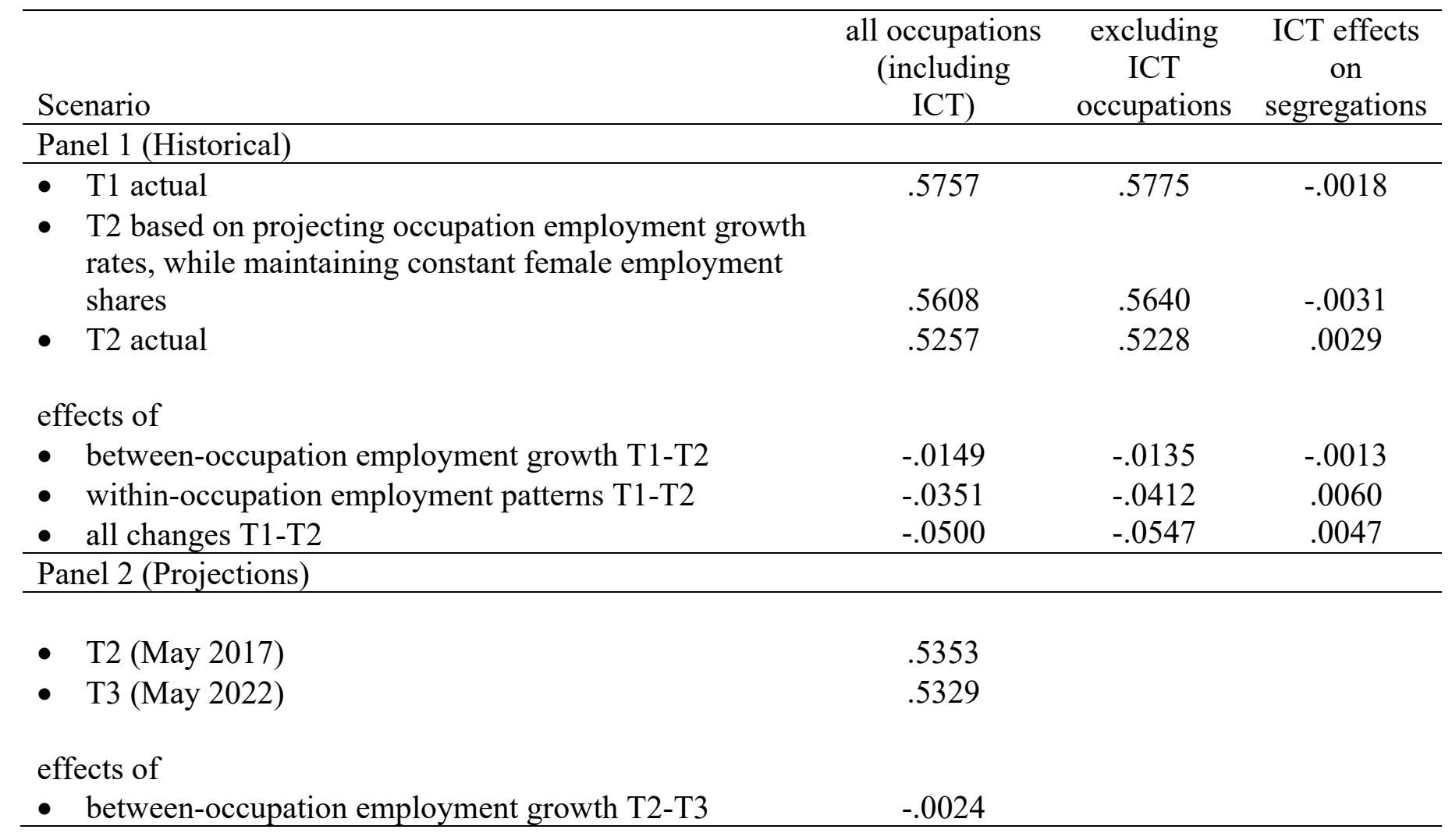

$\mathrm{T} 1=$ the triennium $1986-87$ to $1988-89$ (ABS data)

$\mathrm{T} 2=$ the triennium 2015-16 to 2017-18 (ABS data) or May 2017 (projections)

$\mathrm{T} 3$ = May 22 (projections) 
Table 5: Composition of employment by gender and skill level, historical data and projections

\begin{tabular}{|c|c|c|c|c|c|c|c|}
\hline & & $\begin{array}{l}\text { Skill } \\
\text { level } 1\end{array}$ & $\begin{array}{l}\text { Skill } \\
\text { level } 2\end{array}$ & $\begin{array}{l}\text { Skill } \\
\text { level } 3\end{array}$ & $\begin{array}{l}\text { Skill } \\
\text { level } 4\end{array}$ & $\begin{array}{l}\text { Skill } \\
\text { level } 5\end{array}$ & Total \\
\hline \multicolumn{8}{|c|}{ Panel 1 (historical) } \\
\hline \multirow[t]{3}{*}{ Men } & $1986-87$ to $88-89$ & $24.6 \%$ & $8.8 \%$ & $25.6 \%$ & $22.6 \%$ & $18.3 \%$ & $100.0 \%$ \\
\hline & $2015-16$ to $17-18$ & $30.2 \%$ & $11.0 \%$ & $21.1 \%$ & $21.6 \%$ & $16.2 \%$ & $100.0 \%$ \\
\hline & change & $5.5 \%$ & $2.1 \%$ & $-4.5 \%$ & $-1.0 \%$ & $-2.1 \%$ & \\
\hline \multirow[t]{3}{*}{ Women } & $1986-87$ to $88-89$ & $21.0 \%$ & $9.0 \%$ & $11.0 \%$ & $33.3 \%$ & $25.7 \%$ & $100.0 \%$ \\
\hline & $2015-16$ to $17-18$ & $32.9 \%$ & $11.3 \%$ & $6.6 \%$ & $31.3 \%$ & $17.8 \%$ & $100.0 \%$ \\
\hline & change & $11.9 \%$ & $2.3 \%$ & $-4.3 \%$ & $-2.0 \%$ & $-7.9 \%$ & \\
\hline \multicolumn{8}{|c|}{ Panel 2 (projections) } \\
\hline \multirow[t]{3}{*}{ Men } & May 2017 & $30.2 \%$ & $10.5 \%$ & $20.9 \%$ & $22.0 \%$ & $16.4 \%$ & $100.0 \%$ \\
\hline & May 2022 & $30.8 \%$ & $10.8 \%$ & $20.3 \%$ & $22.0 \%$ & $16.0 \%$ & $100.0 \%$ \\
\hline & change & $0.6 \%$ & $0.3 \%$ & $-0.5 \%$ & $0.0 \%$ & $-0.3 \%$ & \\
\hline \multirow[t]{3}{*}{ Women } & May 2017 & $33.3 \%$ & $10.8 \%$ & $6.5 \%$ & $31.4 \%$ & $18.0 \%$ & $100.0 \%$ \\
\hline & May 2022 & $34.4 \%$ & $10.7 \%$ & $6.1 \%$ & $31.6 \%$ & $17.2 \%$ & $100.0 \%$ \\
\hline & change & $1.1 \%$ & $0.0 \%$ & $-0.4 \%$ & $0.1 \%$ & $-0.8 \%$ & \\
\hline
\end{tabular}

